\title{
Los inhibidores del SGLT-2 y los agonistas del receptor GLP-1 disminuyen la mortalidad en pacientes con diabetes mellitus tipo 2
}

SGLT-2 inhibitors and GLP-1 receptor agonists decrease mortality in patients with type 2 diabetes

\section{Comentado de:}

Palmer SC, BMJ. 2021 Jan 13;372:m4573. PMID:33441402. ${ }^{1}$

\section{Objetivo}

Evaluar los riesgos y beneficios de los inhibidores del cotransportador de sodio-glucosa-2 (SGLT-2) y de los agonistas del receptor del péptido similar al glucagón-1 (GLP-1) en pacientes con diabetes mellitus tipo 2 (DM2) con riesgo cardiovascular y renal variable.

\section{Diseño}

Revisión sistemática y meta-análisis en red.

\section{Fuentes de datos}

Medline, Embase y el Registro Cochrane Central de Ensayos Controlados desde marzo de 2016 hasta agosto de 2020, sin restricción de idioma.

\section{Selección de estudios}

Los autores incluyeron ensayos clínicos controlados aleatorizados (ECA) que compararon inhibidores de SGLT-2 o agonistas del receptor de GLP-1 entre sí o con placebo, tratamiento estándar $u$ otro tratamiento para reducir la glucosa en adultos con DM2, con un seguimiento de al menos 24 semanas. No fueron detallados los criterios de exclusión.

\section{Extracción de datos}

Para cada estudio elegible, dos revisores extrajeron de forma independiente las características del estudio, la población inclui$\mathrm{da}$, las intervenciones evaluadas y los resultados. Los revisores resolvieron los desacuerdos mediante discusión o, en caso necesario, apelando a un tercer revisor. Dos revisores evaluaron de manera independiente el riesgo de sesgo utilizando la herramienta Cochrane para ECA.

\section{Resultados principales}

Fueron incluidos 764 estudios que incorporaron un total de 421.346 pacientes. La Tabla 1 resume los principales resultados.

Tabla 1. Efectos absolutos y relativos basados en el riesgo cardiovascular y renal sobre la mortalidad global de los inhibidores del SGLT-2 y los agonistas del receptor del GLP-1 comparados con placebo o entre sí. Notas: ${ }^{a}$ categorías de riesgo para estimar los efectos absolutos del tratamiento sobre los resultados cardiovasculares y renales: muy bajo riesgo ( $<3$ factores de riesgo cardiovascular), bajo riesgo ( $\geq 3$ factores de riesgo cardiovascular), riesgo moderado (enfermedad cardiovascular), alto riesgo (enfermedad renal crónica: filtrado glomerular reducido o proteinuria), muy alto riesgo (enfermedad cardiovascular y renal crónica) ${ }^{b}$ eventos cada 1.000 pacientes; IC: intervalo de confianza; RRA: reducción del riesgo absoluto.

\begin{tabular}{|c|c|c|c|c|c|c|}
\hline Comparación & $\begin{array}{l}\text { Riesgo relativo } \\
\text { (IC } 95 \% \text { ) }\end{array}$ & Riesgo basal $^{a}$ & $\begin{array}{l}\text { Incidencia grupo } \\
\text { control }^{b}\end{array}$ & $\begin{array}{l}\text { Incidencia grupo } \\
\text { intervención }\end{array}$ & RRA (IC $95 \%)^{b}$ & $\begin{array}{l}\text { Certeza de evidencia } \\
\text { (GRADE) }\end{array}$ \\
\hline \multirow{5}{*}{$\begin{array}{l}\text { Inhibidores } \\
\text { SGLT-2 vs } \\
\text { placebo }\end{array}$} & \multirow[t]{5}{*}{$\begin{array}{c}0,77 \\
(0,71 \text { a } 0,83)\end{array}$} & Muy bajo & 20 & 15 & 5 (6 a 3) & $\begin{array}{c}\text { Moderada por } \\
\text { indirecta }\end{array}$ \\
\hline & & Bajo & 70 & 55 & 15 (11 a 19) & Alta \\
\hline & & Moderado & 120 & 95 & 25 (18 a 32) & Alta \\
\hline & & Alto & 170 & 136 & 34 (25 a 43) & Alta \\
\hline & & Muy alto & 265 & 217 & $48(35$ a 61$)$ & Alta \\
\hline \multirow{5}{*}{$\begin{array}{l}\text { Agonistas del } \\
\text { receptor GLP-1 vs } \\
\text { placebo }\end{array}$} & \multirow[t]{5}{*}{$\begin{array}{c}0,88 \\
(0,83 \text { a } 0,94)\end{array}$} & Muy bajo & 20 & 18 & 2 (1 a 3) & $\begin{array}{c}\text { Moderada por } \\
\text { indirecta }\end{array}$ \\
\hline & & Bajo & 70 & 62 & $8(4$ a 11$)$ & Alta \\
\hline & & Moderado & 120 & 107 & $13(6$ a 18$)$ & Alta \\
\hline & & Alto & 170 & 153 & 17 (9 a 25) & Alta \\
\hline & & Muy alto & 265 & 241 & 24 (12 a 35) & Alta \\
\hline \multirow{5}{*}{$\begin{array}{l}\text { Inhibidores } \\
\text { SGLT-2 vs } \\
\text { agonistas } \\
\text { receptor GLP-1 }\end{array}$} & \multirow[t]{5}{*}{$\begin{array}{c}0,88 \\
(0,79 \text { a } 0,98)\end{array}$} & Muy bajo & 18 & 16 & 2 (1 a 4) & $\begin{array}{l}\text { Moderada por } \\
\text { indirecta }\end{array}$ \\
\hline & & Bajo & 62 & 55 & 7 (2 a 12) & Alta \\
\hline & & Moderado & 107 & 95 & 12 (3 a 21) & Alta \\
\hline & & Alto & 153 & 137 & 16 (4 a 28$)$ & Alta \\
\hline & & Muy alto & 241 & 218 & 23 (6 a 40$)$ & Alta \\
\hline
\end{tabular}


Los autores estimaron el riesgo absoluto basal por cada 1.000 pacientes tratados durante cinco años, asumiendo un riesgo anual constante del desenlace seleccionado para cada año hasta los cinco años. Todos los resultados hacen referencia a la adición de inhibidores de SGLT-2 y agonistas del receptor de GLP-1 a los tratamientos existentes para la diabetes.

Ambas clases de fármacos redujeron la mortalidad por todas las causas, la mortalidad cardiovascular, el infarto de miocardio no mortal y la progresión a la insuficiencia renal terminal. Algunas diferencias notables entre los dos agentes incluyeron que los inhibidores de SGLT-2 redujeron la mortalidad y el ingreso hospitalario por insuficiencia cardíaca más que los agonistas del receptor de GLP-1, y que los agonistas del receptor de GLP-1 redujeron el riesgo de accidente cerebrovascular no fatal más que los inhibidores de SGLT-2 (que aparecieron no tener ningún efecto). Los inhibidores de SGLT-2 y los agonistas del receptor de GLP-1 podrían reducir el peso corporal (evidencia de certeza baja). En cuanto a los efectos adversos, los inhibidores de SGLT-2 causaron infección genital (evidencia de certeza alta), mientras que los agonistas del receptor de GLP-1 podrían causar eventos gastrointestinales graves (evidencia de certeza baja).

Los autores de la revisión encontraron poca o ninguna evidencia del efecto de las intervenciones evaluadas en otros desenlaces importantes para los pacientes, como la amputación de extre- midades, la ceguera, las enfermedades oculares, el dolor neuropático o la calidad de vida relacionada con la salud. Por otro lado, no encontraron evidencia de inconsistencia o heterogeneidad de la red global, excepto en la calidad de vida relacionada con la salud, ni tuvieron preocupaciones serias acerca de la posibilidad de incoherencia entre la evidencia directa e indirecta.

\section{Conclusiones}

En pacientes con DM2, los inhibidores de SGLT-2 y los agonistas del receptor de GLP-1 redujeron la mortalidad global y de causa cardiovascular, así como los eventos cardiovasculares y renales, aunque la magnitud de los beneficios que estuvieron determinados por el riesgo basal de los pacientes y sus perfiles de seguridad fueron diferentes.

Fuentes de financiamiento / Conflicto de interés de los autores: La revisión sistemática no recibió financiamiento específico. Algunos de sus autores declararon haber recibido subsidios y/o salarios de compañías tales como Novo Nordisk, Sanofi, AstraZeneca, Pikdare, AlfaSigma, Baxter Healthcare, Fresenius Medical Care, Amgen, AWAK, BoehringerIngelheim, Lilly. Uno de los autores reportó estar en el comité asesor de Bayer Australia y AstraZeneca, y ser orador honorario de Bayer Australia y Pfizer.

\section{Comentario}

Durante décadas, el control de la DM2 tuvo objetivos de tratamiento focalizados en valores de laboratorio: la glucemia y la hemoglobina glicosilada. Sin embargo, ECA recientes de alta calidad desafían este paradigma glucocéntrico, con resultados que sugieren que el control glucémico intensivo no siempre se correlaciona con una reducción de los complicaciones macrovasculares, y que, inclusive, éste puede asociarse con daños ${ }^{2,3}$.

Los resultados de la revisión sistemática resumida ${ }^{1}$ sobre el uso de los inhibidores de SGLT-2 y los agonistas del receptor de GLP-1 en pacientes con DM2 proponen la necesidad de un cambio desde el enfoque tradicional sobre el control glucémico, a un enfoque dirigido a obtener una reducción absoluta de la morbi-mortalidad, como las complicaciones cardiovasculares y enfermedad renal crónica. Esta perspectiva ya está siendo incorporada a guías de práctica clínica que aconsejan diferentes intervenciones terapéuticas de acuerdo al riesgo cardiovascular basal de los pacientes con diabetes ${ }^{4}$. De hecho, los beneficios potenciales de estas familias de fármacos están siendo también estudiados en pacientes sin diabetes con insuficiencia cardíaca o renal.

\section{Conclusiones de la comentadora}

Los inhibidores de SGLT-2 y los agonistas del receptor de GLP-1 en pacientes con DM2 demostraron, con evidencia de alta calidad, disminuir la mortalidad global, la mortalidad cardiovascular, y la progresión a insuficiencia renal terminal, por un efecto inherente a estos fármacos. Dado que el beneficio está relacionado con la magnitud del riesgo basal del paciente, en pacientes con DM2 con enfermedad renal y/o cardiovascular establecida habría que considerar la adición de estos fármacos independientemente de sus valores de glucemia.

Antonella Stellardo [ Hospital Italiano de Buenos Aires, Servicio de Medicina Familiar y Comunitaria. antonella.stellardo@hospitalitaliano.org.ar ]

Stellardo A. Los inhibidores del SGLT-2 y los agonistas del receptor GLP-1 disminuyen la mortalidad en pacientes con diabetes mellitus tipo 2. Evid Actual Pract Ambul. 2021;24(4):e002151. Available from: https://dx.doi.org/10.51987/EVIDENCIA.V25I1.6977. Comentado de: Palmer SC, et al. Sodiumglucose cotransporter protein-2 (SGLT-2) inhibitors and glucagon-like peptide-1 (GLP-1) receptor agonists for type 2 diabetes: systematic review and network meta-analysis of randomised controlled trials. BMJ. 2021 Jan 13;372:m4573. doi: 10.1136/bmj.m4573. PMID: 33441402; PMCID: PMC7804890.

\section{Referencias}

1. Palmer SC, Tendal B, Mustafa RA. Sodium-glucose cotransporter protein-2 (SGLT-2) inhibitors and glucagon-like peptide-1 (GLP-1) receptor agonists for type 2 diabetes: systematic review and network meta-analysis of randomised controlled trials. BMJ. 2021;372:4573. Available from: 10.1136/bmj. m4573.

2. Rodríguez-Gutiérrez R, Montori VM. Glycemic control for patients with type 2 diabetes mellitus: our evolving faith in the face of evidence. Circ Cardiovasc Qual Outcomes. 2016;9:27553599. Available from: 10.1161/CIRCOUTCOMES.116.002901.

3. Rodriguez-Gutierrez R, Gonzalez-Gonzalez JG, Zuñiga-Hernandez JA, et al. Benefits and harms of intensive glycemic control in patients with type 2 diabetes. BMJ. 2019;367:5887. Available from: 10.1136/bmj.15887.

4. Li S, Vandvik PO, Lytvyn L. SGLT-2 inhibitors or GLP-1 receptor agonists for adults with type 2 diabetes: a clinical practice guideline. BMJ. 2021;373:109-109. Available from: 10.1136/bmj.n1091. 